\title{
The impact of in-canopy wind profile formulations on heat flux estimation in an open orchard using the remote sensing-based two-source model
}

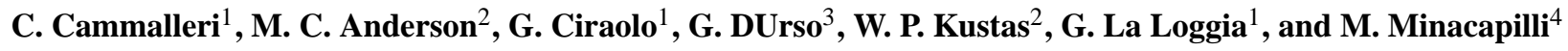 \\ ${ }^{1}$ Department of Hydraulic Engineering and Environmental Applications (DIIAA), Università degli Studi di Palermo, \\ Palermo, Italy \\ ${ }^{2}$ US Department of Agriculture, Agricultural Research Service, Hydrology and Remote Sensing Laboratory, \\ Beltsville, MD, USA \\ ${ }^{3}$ Department of Agricultural Engineering and Agronomy, Università degli Studi di Napoli "Federico II", Naples, Italy \\ ${ }^{4}$ Department of Engineering and Agro-Forest Technology (ITAF), Università degli Studi di Palermo, Palermo, Italy
}

Received: 21 June 2010 - Published in Hydrol. Earth Syst. Sci. Discuss.: 16 July 2010

Revised: 5 November 2010 - Accepted: 14 December 2010 - Published: 22 December 2010

\begin{abstract}
For open orchard and vineyard canopies containing significant fractions of exposed soil ( $>50 \%$ ), typical of Mediterranean agricultural regions, the energy balance of the vegetation elements is strongly influenced by heat exchange with the bare soil/substrate. For these agricultural systems a "two-source" approach, where radiation and turbulent exchange between the soil and canopy elements are explicitly modelled, appears to be the only suitable methodology for reliably assessing energy fluxes. In strongly clumped canopies, the effective wind speed profile inside and below the canopy layer can strongly influence the partitioning of energy fluxes between the soil and vegetation components. To assess the impact of in-canopy wind profile on model flux estimates, an analysis of three different formulations is presented, including algorithms from Goudriaan (1977), Massman (1987) and Lalic et al. (2003). The in-canopy wind profile formulations are applied to the thermal-based two-source energy balance (TSEB) model developed by Norman et al. (1995) and modified by Kustas and Norman (1999). High resolution airborne remote sensing images, collected over an agricultural area located in the western part of Sicily (Italy) comprised primarily of vineyards, olive and citrus orchards, are used to derive all the input parameters needed to apply the TSEB. The images were acquired from June to October 2008 and include a relatively wide range of meteorological and soil moisture conditions. A preliminary sensitivity analysis of
\end{abstract}

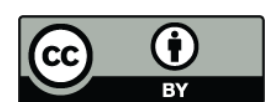

Correspondence to: C. Cammalleri (cammillino@gmail.com) the three wind profile algorithms highlights the dependence of wind speed just above the soil/substrate to leaf area index and canopy height over the typical range of canopy properties encountered in these agricultural areas. It is found that differences among the models in wind just above the soil surface are most significant under sparse and medium fractional cover conditions (15-50\%). The TSEB model heat flux estimates are compared with micro-meteorological measurements from a small aperture scintillometer and an eddy covariance tower collected over an olive orchard characterized by moderate fractional vegetation cover $(\approx 35 \%)$ and relatively tall crop $(\approx 3.5 \mathrm{~m})$. TSEB fluxes for the $7 \mathrm{im}$ age acquisition dates generated using both the Massman and Goudriaan in-canopy wind profile formulations give close agreement with measured fluxes, while the Lalic et al. equations yield poor results. The Massman wind profile scheme slightly outperforms that of Goudriaan, but it requires an additional parameter accounting for the roughness sub-layer of the underlying vegetative surface. The analysis also suggests that within-canopy wind profile model discrepancies become important, in terms of impact on modelled sensible heat flux, only for sparse canopies with moderate vegetation coverage.

\section{Introduction}

In Mediterranean cropping systems, which frequently experience both high levels of moisture stress and insufficient water supply for irrigation, a detailed estimation of crop water requirements can result in a significant reduction of agricultural

Published by Copernicus Publications on behalf of the European Geosciences Union. 
waste of water. This type of information facilitates assessment of irrigation performance indicators at both field and farm scales, fundamental for agricultural economic system performance evaluation (Bastiaanssen and Bos, 1999).

However, many of these Mediterranean cropping systems are characterized by strongly clumped canopy cover, with significant exposure of bare soil between crop rows. Reliable algorithms for estimating total evapotranspiration (ET) therefore require a methodology to estimate water and energy fluxes from both the soil/substrate and the vegetation canopy. Moreover, given that only the vegetation transpiration component of ET is directly related to the effective crop stress condition, accurate partitioning between soil evaporation and canopy transpiration will have added value for agricultural water management monitoring and applications.

Remote sensing provides a means for mapping spatial distributions in water loss from soil and vegetation (e.g., Schmugge et al., 2002). Numerous remote sensing-based approaches to ET mapping have been reported in the literature (Kalma et al., 2008), many of which use thermalinfrared to provide a key surface boundary condition (Kustas and Norman, 1996). Some have been developed to maximize ease of application, using semi-empirical (e.g., Roenink et al., 2000) or within-scene scaling (Allen et al., 2007; Bastiaanssen et al., 1998) approaches, whereas others are more physically based, explicitly modelling the soil-vegetationatmosphere exchange processes (Chehbouni et al., 2001; Norman et al., 1995).

Recent studies (e.g., Choi et al., 2009; Minacapilli et al., 2009; Timmermans et al., 2007) have emphasized the need for so-called "two-source" modelling schemes in order to obtain a more accurate partitioning of the surface energy fluxes in partially vegetated areas. The combination of patchy vegetation cover and frequent dry surface moisture conditions in arid or semi-arid climates causes a significant source of sensible heat flux from the soil surface, which will likely have a measureable influence on the canopy fluxes (Kustas and Norman, 1999). To reliably capture these effects in a modelling framework, an explicit treatment of the soil and vegetation exchange processes in the canopy air-space is required. In such cases the wind speed profile function within the canopy layer will strongly modulate the resistance to heat transport from the soil and canopy elements, and can have a significant impact on both the radiative and turbulent heat exchange between soil and vegetation.

Past studies of the wind speed inside the canopy, especially in forested ecosystems, have been based on experimental observations and subsequent modelling of wind profile using analytical and semi-empirical extinction formulations (e.g., Cowan, 1968; Fons, 1940; Petit et al., 1976). However, the extreme variability in forest canopies results in large disparities in wind speed profiles due to differences in canopy architecture, density, height and foliage distributions (Fritschen, 1985). Despite this variability, a variety of analytical (Cowan, 1968; de Bruin and Moore, 1985; Massman,
1987) and semi-empirical (Uchijima and Wright, 1964) incanopy wind profile formulations have been proposed, with the goal of minimizing the number of input parameters required to describe wind profiles over a range of forest canopy conditions.

Tall and clumped (and/or patchy) crops, such as vineyards and orchards, are in many ways similar to forested environments, and require careful treatment of soil/canopy flux partitioning. An analysis of the impact of different in-canopy wind profiles parameterizations on modelled energy fluxes from the soil and vegetation components provides insight into the uncertainty in heat flux estimation, especially under partial canopy cover.

The study area examined here, located in south-west Sicily (Italy), is comprised of olive and citrus orchards, vineyards and bare soil fields with a wide range in fractional vegetation cover and canopy height typical of Mediterranean systems. Here, flux observations from two micro-meteorological installations (a small aperture scintillometer and an eddy covariance tower) in an olive orchard are used to evaluate the impact of three different in-canopy wind profile algorithms on the heat fluxes estimated using the two-source energy balance (TSEB) model (Kustas and Norman, 1999; Norman et al., 1995). The olive orchard had a canopy height of about $3.5 \mathrm{~m}$ and a fractional vegetation cover of about $35 \%$. High resolution airborne imagery in the visible, near-infrared and thermal-infrared bands was collected on seven dates, covering a wide range of meteorological (e.g., wind speed and air temperature) and stress conditions (water availability due to irrigation and rainfall) and were used to run the TSEB model. The high spatial resolution of the images (on the order of $10 \mathrm{~m}$ ) permits the application of the TSEB model at the sub-field scale despite the high spatial fragmentation of the landscape, mainly characterized by field sizes of less than 5 hectares.

\section{Methodology}

In this section a brief description of the TSEB model will be given, with focused attention on its applicability to sparse, clumped vegetation. In addition, an overview of the different formulations for modelling in-canopy wind profile through the canopy layer is provided, with special consideration for the canopy air space in between individual trees.

\subsection{Model description}

The solution of the surface energy balance based on the two-source approach requires partitioning the energy fluxes between the canopy and soil components of the modelling scene:

$R_{\mathrm{n}, \mathrm{s}}-G_{0}=H_{\mathrm{s}}+\lambda E_{\mathrm{s}}$

$R_{\mathrm{n}, \mathrm{c}}=H_{\mathrm{c}}+\lambda E_{\mathrm{c}}$ 


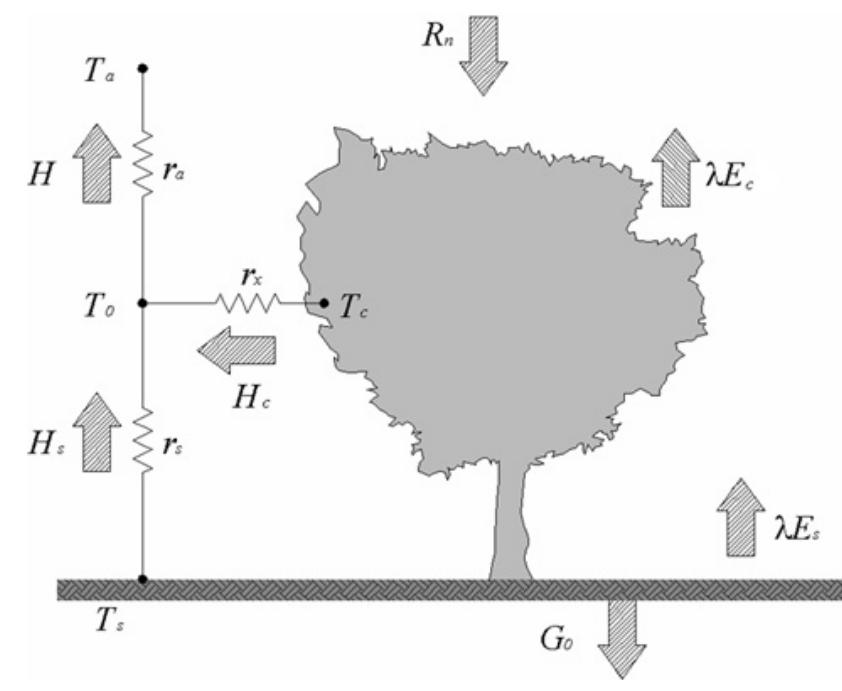

Fig. 1. Scheme of the resistance network and key energy balance variables used in the TSEB model.

where $R_{\mathrm{n}}$ and $H$ represent the net radiation and the sensible heat flux $\left[\mathrm{W} \mathrm{m}^{-2}\right]$ respectively for the canopy layer and soil (defined by the subscript c and s, respectively), $G_{0}$ is the soil heat flux $\left[\mathrm{W} \mathrm{m}^{-2}\right], \lambda E_{\mathrm{c}}$ is the latent heat flux from the canopy layer $\left[\mathrm{W} \mathrm{m}^{-2}\right]$, representing the crop transpiration, and $\lambda E_{\mathrm{s}}$ is the latent heat flux from soil $\left[\mathrm{W} \mathrm{m}^{-2}\right]$, representing the soil evaporation. Energy stored in the vegetative canopy and consumed in photosynthesis is neglected in Eq. (2). The solution of Eqs. (1) and (2) involves estimation of the net radiation components and soil heat flux based on radiation inputs and canopy extinction. Sensible heat is computed using the temperature-resistance network shown in Fig. 1, with latent heat determined as a residual to the overall energy balance. The solution sequence was described by Norman et al. (1995) with revisions by Kustas and Norman (1999), and it is outlined briefly below.

In the TSEB, the partitioning of net radiation between the soil and canopy net radiation is physically based and considers separately the divergence of the short-wave $\left(S_{\mathrm{n}}\right)$ and long-wave radiation $\left(L_{\mathrm{n}}\right)$ within the canopy layer, following the latest TSEB version proposed by Kustas and Norman (2000). Net short-wave radiation is computed using a simplified version of the relationships reported in Chapter 15 of Campbell and Norman (1998):

$S_{\mathrm{n}, \mathrm{s}}=\left(1-\alpha_{\mathrm{s}}\right) R_{\mathrm{S}} \exp (-k \mathrm{LAI})$

$S_{\mathrm{n}, \mathrm{c}}=\left(1-\alpha_{\mathrm{c}}\right) R_{\mathrm{s}}[1-\exp (-k \mathrm{LAI})]$

where $k$ is the extinction coefficient for solar radiation modelled as a function of solar zenith angle, $\theta_{\mathrm{s}}$ (Norman and Campbell, 1983), $\alpha_{\mathrm{c}}$ and $\alpha_{\mathrm{s}}$ are the canopy and soil albedo and LAI is the leaf area index $\left[\mathrm{m}^{2} \mathrm{~m}^{-2}\right]$.
Net long-wave radiation has been computed using the formulation proposed by Ross (1975) assuming exponential extinction law of radiation in canopy air-space:

$$
\begin{aligned}
& L_{\mathrm{n}, \mathrm{s}}=\exp \left(-k_{\mathrm{L}} \mathrm{LAI}\right) \varepsilon^{\prime} \sigma T_{\mathrm{a}}^{4}+\left[1-\exp \left(-k_{\mathrm{L}} \mathrm{LAI}\right)\right] \varepsilon_{\mathrm{c}} \sigma T_{\mathrm{c}}^{4}-\varepsilon_{\mathrm{s}} \sigma T_{\mathrm{s}}^{4} \\
& L_{\mathrm{n}, \mathrm{c}}=\left[1-\exp \left(-k_{\mathrm{L}} \mathrm{LAI}\right)\right]\left(\varepsilon^{\prime} \sigma T_{\mathrm{a}}^{4}+\varepsilon_{\mathrm{s}} \sigma T_{\mathrm{s}}^{4}-2 \varepsilon_{\mathrm{c}} \sigma T_{\mathrm{c}}^{4}\right)
\end{aligned}
$$

where $k_{\mathrm{L}}$ is the extinction coefficient in the long-wave $(\approx$ $0.95), \varepsilon^{\prime}$ is the apparent atmospheric emissivity (modelled by using the approach proposed by Brutsaert, 1982), $\sigma$ is the Stefan-Boltzmann constant, $\varepsilon_{\mathrm{c}}(\approx 0.98)$ and $\varepsilon_{\mathrm{s}}(\approx 0.97)$ are the surface emissivity of canopy and soil respectively (Brutsaert, 1982), $T_{\mathrm{a}}[\mathrm{K}]$ is the air temperature above the canopy, and $T_{\mathrm{c}}$ and $T_{\mathrm{S}}[\mathrm{K}]$ are the surface temperatures of canopy and soil, respectively.

The soil heat flux, $G_{0}$, can be related to the net radiation at the soil surface following the approach proposed by Santanello and Friedl (2003):

$G_{0}=A \cos [2 \pi(t+C) / B] R_{\mathrm{n}, \mathrm{s}}$

where $t$ is the time in seconds relative to the solar noon, $A$ represents the maximum of the ratio $G_{0} / R_{\mathrm{n}, \mathrm{s}}$, assumed equal to 0.2 in agreement with the range of variability derived by the studies of Choudhury et al. (1987), Friedl (1996), Kustas and Daughtry (1990), $C$ [s] is the peak in time position, supposed equal to 3600 following Cellier et al. (1996), and $B$ [s] is set equal to 74000 .

These relationships were originally developed for a surface characterized by uniformly distributed vegetation cover. In the case of clumped canopies with partial vegetation cover, the LAI can be corrected by means of a multiplicative clumping factor, $\Omega$, which takes into account reduced extinction through a clumped canopy compared to uniformly distributed vegetation. To compute the clumping factor, Campbell and Norman (1998) suggest the following semiempirical expression:

$\Omega\left(\theta_{\mathrm{s}}\right)=\frac{\Omega(0)}{\Omega(0)+[1-\Omega(0)] \exp \left[-2.2\left(\theta_{\mathrm{s}}\right)^{\mathrm{p}}\right]}$

where $\Omega\left(\theta_{\mathrm{s}}\right)$ is the clumping factor at solar zenith angle $\theta_{\mathrm{s}}$, $\Omega(0)$ is the clumping factor for a nadir solar zenith angle, and $p$ is an empirical expression given by:

$p=3.8-0.46 D$

where $D$ is the plant height to width ratio, given as:

$D=\frac{\mathrm{h}_{\mathrm{c}}}{w_{\mathrm{v}}}=\frac{h_{\mathrm{c}}}{s_{\text {row }} f_{\mathrm{c}}}$

and $h_{\mathrm{c}}$ is vegetation height $[\mathrm{m}]$ and $w_{\mathrm{v}}$ is typical vegetation clump width [m]. In row crops, $w_{\mathrm{v}}$ can be estimated as $s_{\text {row }} f_{\mathrm{c}}$, where $s_{\text {row }}[\mathrm{m}]$ is the mean row spacing of the crops (estimated from a land-use map) and $f_{\mathrm{c}}$ is the fraction cover derivable from vegetation indices (e.g., NDVI). The clumping factor for nadir solar zenith angle can be estimated from 
the total LAI and fraction vegetation coverage. In the following sections, the term LAI refers always to the clumped value, $\Omega\left(\theta_{\mathrm{s}}\right)$ LAI.

The sensible heat flux, $H$, is expressed as the sum of the contributions of soil, $H_{\mathrm{s}}$, and canopy, $H_{\mathrm{c}}$, accordingly with the assumption of "series" resistance network scheme (Shuttleworth and Wallace, 1985):

$H=H_{\mathrm{c}}+H_{\mathrm{s}}=\rho c_{\mathrm{p}} \frac{T_{0}-T_{\mathrm{a}}}{r_{\mathrm{a}}}=\rho c_{\mathrm{p}}\left(\frac{T_{\mathrm{c}}-T_{0}}{r_{\mathrm{x}}}+\frac{T_{\mathrm{s}}-T_{0}}{r_{\mathrm{s}}}\right)$

where $\rho$ is the air density $\left[\mathrm{kg} \mathrm{m}^{-3}\right], c_{\mathrm{p}}$ is the specific heat at constant pressure $\left[\mathrm{J} \mathrm{kg}^{-1} \mathrm{~K}^{-1}\right], T_{0}$ is the surface aerodynamic temperature $[\mathrm{K}], r_{\mathrm{a}}$ is the aerodynamic resistance $\left[\mathrm{s} \mathrm{m}^{-1}\right], r_{\mathrm{s}}$ is the resistance to the heat transfer in the air space between soil and source height $\left[\mathrm{s} \mathrm{m}^{-1}\right]$ and $r_{\mathrm{x}}$ is the resistance of canopy boundary layer [ $\mathrm{s} \mathrm{m}^{-1}$ ] (Goudriaan, 1977; Kustas and Norman, 1999; McNaughton and van den Hurk, 1995; Norman et al., 1995). In order to obtain $T_{\mathrm{s}}$ and $T_{\mathrm{c}}$ in Eq. (11) the radiometric surface temperature, $T_{\mathrm{RAD}}$, retrieved by remote sensing is partitioned into soil and canopy components based on the vegetation cover fraction, $f_{\mathrm{c}}(\theta)$, apparent at the view zenith angle of the thermal radiometer $(\theta)$ :

$T_{\mathrm{RAD}}=\left[f_{\mathrm{c}}(\theta) T_{\mathrm{c}}^{4}+\left(1-f_{\mathrm{c}}(\theta)\right) T_{\mathrm{s}}^{4}\right]^{1 / 4}$

In this experiment, $\theta=0$ was used since the airborne sensors were at near-nadir view angles, and $f_{\mathrm{c}}(\theta)$ was derived from LAI using (Choudhury, 1987; Richter and Timmermans, 2009):

$f_{\mathrm{c}}(0)=1-\exp (-0.5 \mathrm{LAI})$

In the case of partial or open canopy cover under strong convective conditions with hot, dry soil, the soil resistance, $r_{\mathrm{s}}$, in Eq. (11) can be estimated following the modification proposed by Kustas and Norman (1999) based on the study of Kondo and Ishida (1997):

$r_{\mathrm{s}}=\frac{1}{c\left(T_{\mathrm{s}}-T_{\mathrm{c}}\right)^{1 / 3}+b^{\prime} U_{\mathrm{s}}}$

where $b^{\prime}$ can be set equal to 0.012 for natural surfaces, and the coefficient $c\left[\mathrm{~m} \mathrm{~s}^{-1} \mathrm{~K}^{-1 / 3}\right]$ ranging between 0.0011 and 0.0038 as a function of the surface roughness. Sauer (1993) and Sauer et al. (1995) suggest a value for $c$ of 0.0025 for surfaces characterized by cultivated crops. The term $U_{\mathrm{s}}\left[\mathrm{m} \mathrm{s}^{-1}\right]$ represents the wind speed just above the soil, where the effect of soil surface roughness is negligible, in general around 0.05 and $0.2 \mathrm{~m}$. The value of $U_{\mathrm{s}}$ can be derived from the wind speed above the canopy by modelling the wind profile inside the foliage space.
The aerodynamic resistance, $r_{\mathrm{a}}$, can be modelled as a function of wind speed, $U\left[\mathrm{~m} \mathrm{~s}^{-1}\right]$, by means of the formulation proposed by Brutsaert (1982):

$r_{\mathrm{a}}=\frac{\left[\ln \left(\frac{z_{\mathrm{U}}-d_{0}}{z_{0 \mathrm{~m}}}\right)-\Psi_{\mathrm{m}}\right]\left[\ln \left(\frac{z_{\mathrm{T}}-d_{0}}{z_{0 \mathrm{~m}}}\right)-\Psi_{\mathrm{h}}\right]}{0.16 U}$

where $z_{\mathrm{T}}$ and $z_{\mathrm{U}}[\mathrm{m}]$ are the measurement height of air temperature and wind speed above the canopy height, $d_{0}$ is the zero plane displacement $[\mathrm{m}], z_{0 \mathrm{~m}}$ is the roughness length for momentum transfer [m], and $\Psi_{\mathrm{h}}$ and $\Psi_{\mathrm{m}}$ are the atmospheric stability functions modelled according to Paulson (1970) and Webb (1970).

The resistance of the canopy boundary layer, $r_{\mathrm{X}}$, is schematized as suggested by Norman et al. (1995), according to the parameterization proposed by McNaughton and van den Hurk (1995):

$r_{\mathrm{x}}=\frac{C^{\prime}}{\mathrm{LAI}}\left(\frac{s}{U_{d_{0}+z_{\mathrm{om}}}}\right)^{1 / 2}$

where $C^{\prime}$ is set equal to $90 \mathrm{~s}^{1 / 2} \mathrm{~m}^{-1}$ as suggested by Grace (1981), $s$ is the mean leaf size [m] and $U_{d_{0}+z_{0 \mathrm{~m}}}$ is the wind velocity at the height $\left(d_{0+} z_{0 \mathrm{~m}}\right)$.

Finally, the set of two Eqs. (11) and (12) in the unknown variables $T_{\mathrm{c}}, T_{\mathrm{S}}$ and $T_{0}$ can be solved along with the overall energy balance in Eqs. (1) and (2) using an initial assumption that the canopy transpiration, $\lambda \mathrm{E}_{\mathrm{c}}$, is at the potential rate estimated using the Priestley-Taylor equation (Priestley and Taylor, 1972). If the canopy is in fact undergoing water stress, the Priestley-Taylor equation will lead to an overestimation of $\lambda \mathrm{E}_{\mathrm{c}}$, which in turn will likely result in an overestimation of $H_{s}$ due to an elevated $T_{\mathrm{S}}$ resulting in negative value of $\lambda E_{\mathrm{s}}$ (condensation) computed via Eq. (1). This condition is not physically realistic during daytime convective conditions and therefore a new solution is obtained by iteratively reducing the Priestley-Taylor coefficient, simulating the effects of canopy stress (see Kustas et al., 2004).

The main parameters used in the TSEB model are summarized in Table 1, along with values or parameterizations adopted in this study.

\subsection{Wind speed above the soil surface}

In the original TSEB formulation the wind speed above the soil layer was modelled using the exponential law proposed by Goudriaan (1977), from here on referred to as the Goudriaan approach:

$U_{\mathrm{s}}=U_{\mathrm{c}} \exp \left[-a\left(1-z_{\mathrm{s}} / h_{\mathrm{c}}\right)\right]$

where $U_{\mathrm{c}}$ represents the wind speed $\left[\mathrm{m} \mathrm{s}^{-1}\right]$ at the top of canopy (derived by logarithmic profile, adjusted by means of stability function), $z_{\mathrm{S}}[\mathrm{m}]$ is the height above the soil where the effect of soil surface roughness becomes negligible, set equal to $0.1 \mathrm{~m}$ for the tall vegetation in this experiment, and $a$ is the extinction factor, given by Goudriaan (1977) as: 
Table 1. Main parameters used in the TSEB model simulations, along with values adopted in this study.

\begin{tabular}{|c|c|c|c|}
\hline Variable & Parameter & Description & Value* \\
\hline \multirow{4}{*}{$R_{\mathrm{n}}$} & $k$ & Extinction coefficient for solar radiation & $0.6 /\left(2 \cos \theta_{\mathrm{S}}\right)^{0.5}$ \\
\hline & $k_{\mathrm{L}}$ & Extinction coefficient in the long-wave & 0.95 \\
\hline & $\varepsilon_{\mathrm{c}}$ & Emissivity of canopy layer & 0.98 \\
\hline & $\varepsilon_{\mathrm{S}}$ & Emissivity of soil layer & 0.97 \\
\hline \multirow{3}{*}{$G_{0}$} & $\mathrm{~A}$ & Maximum ratio $G_{0} / R_{\mathrm{n}, \mathrm{s}}$ & 0.2 \\
\hline & $\mathrm{B}[\mathrm{s}]$ & $G_{0}$ peak in time position & 3600 \\
\hline & $\mathrm{C}[\mathrm{s}]$ & Parameter for $G_{0}$ estimation & 74000 \\
\hline \multirow[b]{2}{*}{$r_{\mathrm{a}}$} & $d_{0}[\mathrm{~m}]$ & Zero plane displacement & $2 / 3 h_{\mathrm{c}}$ \\
\hline & $z_{0 \mathrm{~m}}[\mathrm{~m}]$ & Roughness length for momentum transfer & $1 / 8 \mathrm{~h}_{\mathrm{c}}$ \\
\hline$r_{\mathrm{X}}$ & $\mathrm{C}^{\prime}\left[\mathrm{s}^{1 / 2} \mathrm{~m}^{-1}\right]$ & Coefficient for leaf boundary-layer resistance & 90 \\
\hline \multirow[b]{2}{*}{$r_{\mathrm{s}}$} & $\mathrm{b}^{\prime}$ & Coefficient for wind speed in $r_{\mathrm{S}}$ & 0.012 \\
\hline & $\mathrm{c}\left[\mathrm{m} \mathrm{s}^{-1} \mathrm{~K}^{-1 / 3}\right]$ & Coefficient for convective velocity in $r_{\mathrm{s}}$ & 0.0025 \\
\hline \multirow{4}{*}{$U_{\mathrm{s}}$} & $z_{\mathrm{s}}[\mathrm{m}]$ & Height above the soil where is minimal the effect of soil surface roughness & 0.1 \\
\hline & $C_{\mathrm{d}}$ & Drag coefficient & 0.2 \\
\hline & $\alpha_{*}$ & Parameter accounting for roughness sub-layer & 1.5 \\
\hline & $z_{\mathrm{d}}[\mathrm{m}]$ & Crown bottom height & $1 / 3 h_{\mathrm{c}}$ \\
\hline
\end{tabular}

* References for the adopted values are recognizable throughout the text.

$a=0.28 \mathrm{LAI}^{2 / 3} h_{\mathrm{c}}^{1 / 3} s^{-1 / 3}$

where $s$ is computed by four times the leaf area divided by the perimeter.

However, as observed by Brutsaert (1982), the use of an exponential wind profile inside the foliage space is not always appropriate, especially in proximity of the soil surface. Moreover, a number of past studies focused attention on wind profile observations for forested canopies and the difficulty of specifying a unified in-canopy wind profile formulation (Fons, 1940; Petit et al., 1976; Shaw, 1977; Uchijima and Wright, 1964). In particular, Shaw (1977) observed that in the lower region of the canopy a hyperbolic-cosine profile may be more appropriate. More recently, Massman (1987) suggested the following expression (from here on referred to as the Massman approach), assuming a uniform vertical distribution of foliage:

$U_{(z)}=U_{\mathrm{c}}\left[\frac{\cosh \left(\beta \frac{z}{h_{\mathrm{c}}}\right)}{\cosh \beta}\right]^{1 / 2} z_{0 \mathrm{~s}}<z \leq h_{\mathrm{c}}$

in which the parameter $\beta$ can be derived by the relationship:

$\beta=\frac{4 C_{\mathrm{d}} \mathrm{LAI}}{0.16 \alpha_{*}^{2}}$

where $C_{\mathrm{d}}$ is the drag coefficient typically equal to 0.2 (Goudriaan, 1977), and $\alpha_{*}$ is a dimensionless coefficient that accounts for the presence of the roughness sub-layer of the underlying vegetative surface, having value between 1.0 and
2.0 (Raupach and Thorm, 1981). Due to the uncertainties in the effective value of this parameter, a value of 1.5 was adopted in this experiment as suggested by Massman (1987) on the basis of observed wind profiles in different crops. The parameter $\beta$, derived using Eq. (20), represents the extinction coefficient for hyperbolic-cosine profile, equivalent to the parameter $a$ of the exponential in Eq. (17).

An analogous, but more complex, relationship exists for the case of a triangular foliage distribution, related to the Airy functions (Abramowitz and Stegun, 1964) above and below the point of maximum foliage density. However, the requirement of knowing the vertical distribution of the foliage restricts the application of this approach to sites having good ground-truth information and is therefore not considered here.

More recently, on the basis of detailed analysis of observed wind profiles acquired inside pine forests in Great Britain and the Shasta Experimental Forest in the USA, Lalic et al. (2003) suggest the following wind profile inside the canopy space (from here on referred to as the Lalic approach):

$U_{(z)}=\left\{\begin{array}{cc}U_{\mathrm{c}}\left[\frac{\cosh \beta\left(\frac{z-z_{\mathrm{d}}}{h_{\mathrm{c}}}\right)}{\cosh \beta}\right]^{7 / 2} & z_{\mathrm{d}}<z \leq h_{\mathrm{c}} \\ C_{\mathrm{c}} U_{\mathrm{c}} & z_{0 \mathrm{~s}}<z \leq z_{\mathrm{d}}\end{array}\right.$

where $z_{\mathrm{d}}[\mathrm{m}]$ is the crown bottom height, the factor $\beta$ is parameterised as in the Massman (1987) approach, and the 
parameter $C_{\mathrm{c}}$ is define as follow:

$C_{\mathrm{c}}=\left[\cosh \beta\left(1-\frac{z_{\mathrm{d}}}{h_{\mathrm{c}}}\right)\right]^{-7 / 2}$

The exponent $7 / 2$ was derived, in replacement of the value of 0.5 proposed by Massman, by fitting the values measured in a forest in Great Britain with the empirical relationship. In the absence of additional information, the parameter $z_{\mathrm{d}}$ was set equal to $1 / 3$ of canopy height, on the hypothesis that for tall canopies the foliage occupies primarily the upper $2 / 3$ of the canopy height.

The relationships described in Eqs. (19) and (21) can be used to derive the value of wind speed just above the soil, analogous to Eq. (17), by replacing the term $z$ with the value $z_{\mathrm{s}}$.

\section{Study area and data collection}

The study site was located in southern Italy in a highly fragmented agricultural landscape, mainly dominated by orchards and vineyards with strongly clumped vegetation cover, set in a typical Mediterranean climate. During the period June-October 2008, 7 airborne remote sensing acquisitions were made as part of the DIFA (DIgitalizzazione della Filiera Agroalimentare) project. In the same timeframe, a series of field campaigns was carried out, aimed at characterizing radiometric, thermal and biophysical surface properties over this landscape, including continuous monitoring of surface energy fluxes by means of micro-meteorological instrumentations.

\subsection{Test site description}

The experiment site, located in south-west cost of Sicily (Italy) about $5 \mathrm{~km}$ south-east of the town of Castelvetrano (TP) at $37^{\circ} 38^{\prime} 35^{\prime \prime} \mathrm{N}$ latitude and $12^{\circ} 50^{\prime} 50^{\prime \prime} \mathrm{E}$ longitude, encompasses an area of approximately 160 ha in size. The crops grown in this region are mainly olive trees, grapes and citrus trees (Fig. 2). The landscape around the study site is generally flat and highly fragmented, with a mean field size of few hectares, alternating between different crop types and fallow fields with bare soil.

From a climatic standpoint, the area experiences a typical Mediterranean climate characterized by moderate rainfall during the autumn and winter periods and by very high air temperature, with little precipitation occurring during the summer months. The phase shift between the crop phenological (growth) cycle and the rainfall events generally results in a high evaporative demand during the summer period, especially if there has been an absence of precipitation during the Spring. For example, in 2008 the total rainfall for the study area was of about $450 \mathrm{~mm}$, while the FAO-56 formula for reference evapotranspiration (Allen et al., 1998) predicts an atmospheric evaporative demand of nearly $1100 \mathrm{~mm}$.

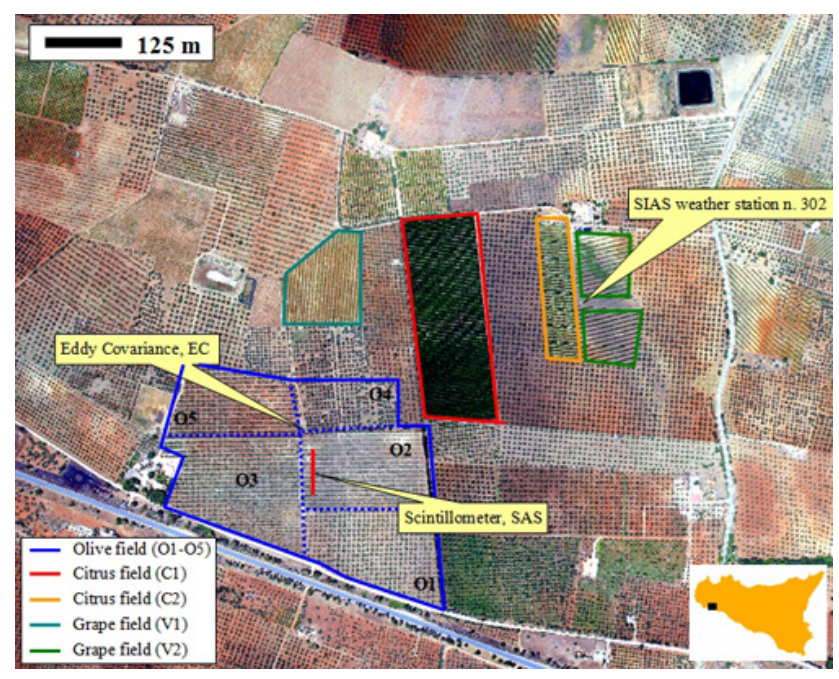

Fig. 2. Orthophoto of the study area. The coloured lines demarcate the main study fields: specifically, the blue line encompasses the olive orchard monitored by the two micro-meteorological installations (denoted as SAS and EC). Additionally the location of the SIAS weather station is demarcated in the eastern part of the study area.

The northern part of the test site mainly consists of olive, grape and bare soil fields of moderate size, with a square shape water body in the east maintained for irrigation purposes (see Fig. 2). In the central area there are alternating fields comprised of vineyards (fields V1 and V2, respectively demarcated by blue marine and green lines), olive and citrus orchards (fields $\mathrm{C} 1$ and $\mathrm{C} 2$, respectively denoted with red and orange lines) with varying fractional vegetation cover, canopy height and field size. In the eastern side of the experimental site there is located a meteorological installation of the SIAS (Servizio Informativo Agrometeorologico Siciliano), which provides measurements of the main meteorological variables (e.g., incoming solar radiation, air temperature, pressure and humidity, wind velocity and rainfall). The southern part of the area is mainly characterized by olive orchards, and in particular an olive field of about 13 ha in size (demarcated by the blue line in Fig. 2) where two different micro-meteorological stations were installed to measure energy fluxes: a small aperture scintillometer (SAS) system and an eddy covariance (EC) tower.

The olive trees have been planted on regular grid of about $8 \times 5 \mathrm{~m}^{2}(\approx 250$ trees/ha). The mean olive canopy height is about $3.3 \mathrm{~m}$ with a mean fractional canopy cover of approximately 0.35 . The entire olive orchard was subdivided into 5 sub-plots, $\mathrm{O} 1$ to O5, in order to analyze the effective homogeneity of the field, which is crucial for assessing whether the micro-meteorological installation provides flux measurements representative of the field average. The sparse configuration of the olive trees, typical of Mediterranean agricultural practices, causes the surface flux exchange mechanism to be 
Table 2. Summary of the in-situ measurements collected during each airborne campaign and accuracy $\left(R^{2}\right)$ of calibration procedures.

\begin{tabular}{lcc}
\hline Variables & \# Sampling sites & $R^{2}$ \\
\hline reflectance & $8-12$ & $0.94-0.99$ \\
$T_{\mathrm{RAD}}[\mathrm{K}]$ & $6-10$ & $0.97-0.99$ \\
$\alpha$ & 7 & 0.99 \\
$\mathrm{LAI}\left[\mathrm{m}^{2} \mathrm{~m}^{-2}\right]$ & 18 & 0.94 \\
$h_{\mathrm{c}}[\mathrm{m}]$ & 18 & 0.79 \\
\hline
\end{tabular}

strongly influenced by sensible heat fluxes coming from the exposed soil, making this a good test case for studying soil resistance and wind profile parameterizations.

\subsection{In-situ measurements}

The measurements collected during the 2008 study period address two primary objectives: (a) characterization of the test site in terms of radiometric, thermal and biophysical properties for the purpose of calibrating the remote sensing data; (b) collection of micrometeorological observations for evaluating TSEB flux predictions.

\subsubsection{Measurements for remote sensing data calibration}

To construct reliable surface reflectance and radiometric surface temperature maps, removing effects of atmospheric absorption and scattering, the aircraft imagery were semiempirically calibrated with respect to in-situ observations. Additionally, retrievals of vegetation properties such as LAI and canopy height were improved using local calibration with ground-truth data.

The ground measurement campaigns were conducted during each of the 7 acquisition days, beginning $2 \mathrm{~h}$ before the acquisition and finishing $2 \mathrm{~h}$ after the aircraft overpass.

Specifically, spectroradiometric measurements were collected with an ASD Inc. FieldSpec ${ }^{\circledR}$ HandHeld spectroradiometer over a number of natural and artificial surfaces with different radiometric characteristics, surface temperature was measured using non-contact thermal-IR radiometers, LAI was measured for different crops using a $\mathrm{Li}$-cor ${ }^{\circledR}$ LAI2000 optical instrument, together with canopy height measurements.

The data were collected at several sites across the study area, selected with the aim to represent the range of variability in the scene of the observed quantity. Multiple repetitions of the observations were collected in order to minimize errors related to the measurement techniques.

Particular care was taken with the measurement of fieldand plant- scale LAI for the olive grove. In fact, due to the strong clumping of these crops, the measurements were structured to characterize separately LAI of a single plant (adopting the protocol suggested in the instrument manual; Li-cor Inc., 1992) and the plot scale value (to average over the clumping effects). The plant-scale values were used to calibrate the images, while the plot-scale values were used to assess the clumping effect.

A linear interpolation (in time) of both spectroradiometric and surface temperature measurements was used for all the ground targets, in order to extrapolate the variables to the time of aircraft overpass. A summary of the observed variables and the number of sites where data were collected are reported in Table 2 .

\subsubsection{Surface energy fluxes measurements}

Surface fluxes in the olive orchard were continuously monitored during the entire study period by means of 2 micrometeorological installations: a small aperture scintillometer and an eddy covariance tower.

The scintillometer system included a Scintec SLS20 displaced beam small aperture scintillometer (SAS), a two component (total incoming and outgoing) pyrradiometer (Schenk $G m b H$, model 8111), and three soil heat plates (HFP01SC, Hukseflux). The SAS was installed at a height of $7 \mathrm{~m}$ above the ground, with a path length of about $95 \mathrm{~m}$; the pyrradiometer was installed in correspondence of SAS transmitter an elevation of $8 \mathrm{~m}$ above ground level (agl), and the three flux plates were set beneath the canopy foliage, in an exposed bare soil area and in an intermediate location, at depth of about $0.10 \mathrm{~m}$ below the ground. Due to the preparation of the soil by ploughing, the heat storage above the plates has been neglected. Data from the three soil plates have been averaged to estimate field-scale representative values. This installation allowed the direct measurements of net radiation and soil heat flux, indirect measurements of sensible heat flux via the Monin-Obukhov surface layer similarity theory (Hartogensis, 2006; Thiermann and Grassl, 1992), and then the derivation of latent heat flux as a residual term of the surface energy balance.

The eddy covariance system (EC) was located in the northern part of the olive field, and is part of the Carboltaly project - an Italian network of eddy covariance installations for monitoring carbon balance in agricultural and forest systems (Papale, 2006). The instruments include a CSAT3-3D sonic anemometer (Campbell Scientific Inc.) and a LI7500 openpath gas analyzer (Li-cor Inc.) installed at an elevation of 8 $\mathrm{m}$ above the ground, a NR-Lite-L net radiometer (Kipp \& Zonen), and two HFP01SC flux plates (HFP01SC, Hukseflux). This installation allowed measurement of all the terms of the surface energy balance. It is well known that in most cases turbulent fluxes measured by the eddy covariance technique suffer from lack of energy balance closure due to a number of factors (Foken et al., 2006). In this experiment, the balance closure was satisfactory (Pernice et al., 2009) with a closure ratio, given by $(H+\lambda E) /\left(R_{\mathrm{n}}+G_{0}\right)$, of approximately 0.87 . 
Table 3. Statistics derived by a comparison of SAS and EC half-hourly fluxes measurements over the full study period (June-October 2008, daytime data only). Average SAS-EC measurements at the time of the aircraft overpasses during the 7 field campaigns are also provided.

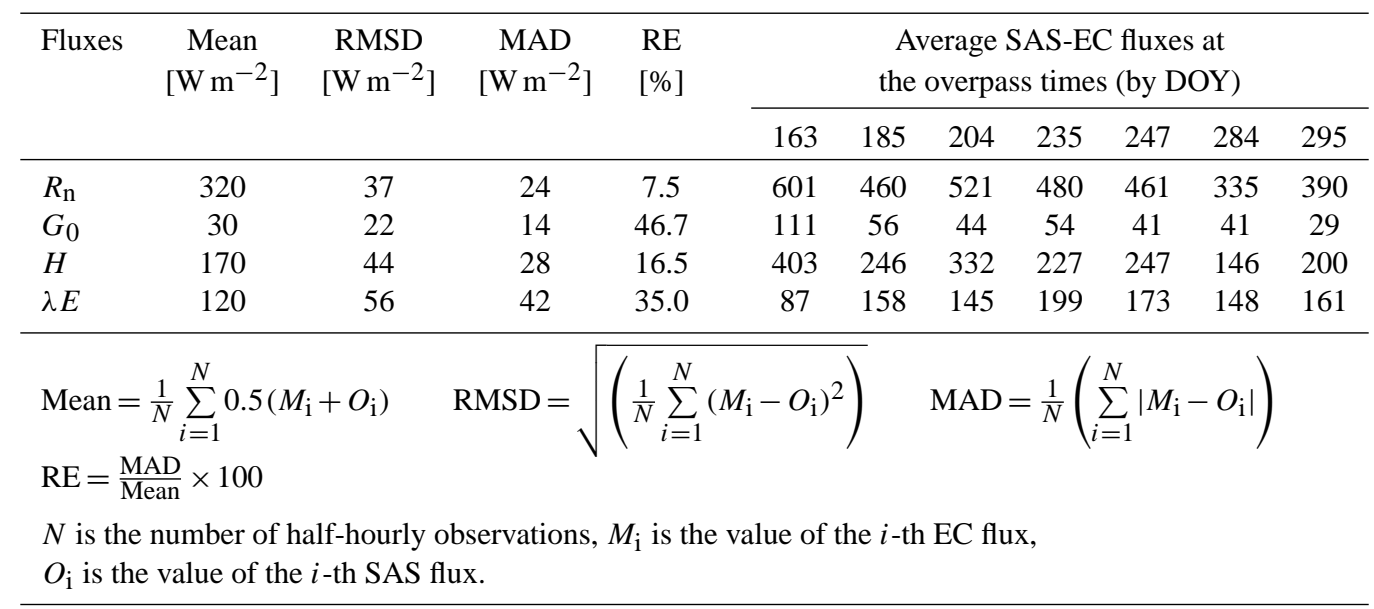

Still, in comparison with TSEB fluxes, EC flux closure was enforced by assigning energy residuals to the latent heat flux (Prueger et al., 2005).

Due to the differences in instrument locations and footprints, the EC and SAS systems generally measured fluxes arising from two distinct source areas within the field. Assuming that flux conditions were generally uniform across the field, flux observations from the two installations were averaged and assumed to be representative of the field average; this hypothesis will be discussed in Sect. 4.2. In Table 3 the SAS-EC average fluxes at the time of the aircraft overpasses are listed.

In order to assess uncertainties in the flux measurements, RMSD (Root Mean Square Difference), MAD (Mean Absolute Difference), and RE (Relative Error) statistics were computed from an EC-SAS flux comparison. Table 3 lists results from this comparison, computed using half-hourly daytime flux measurements from June to October 2008.

The RMSD and RE values computed for $R_{\mathrm{n}}, G_{0}$, and $H$ listed in Table 3 are consistent with typical uncertainties derived in flux measurement system intercomparisons (e.g., Twine et al., 2000). High RE values for $G_{0}$ reflect the relatively small magnitude of this flux, but absolute indicators suggest reasonable agreement. Discrepancies in latent heat flux are the largest, due in part to $\lambda E$ from the SAS is computed as a residual, and therefore accumulates errors in all measured flux components, and the EC technique lacking energy balance closure.

\subsection{Airborne remote sensing data processing}

The airborne remote sensing data acquisitions were collected by "Terrasystem s.r.l." using a SKY ARROW 650 TC/TCNS aircraft, at a height of nearly $1000 \mathrm{~m}$ agl. The platform has on board a multispectral camera Duncantech MS4100 with
3 spectral bands at Green (G, 530-570 nm), Red (R, 650$690 \mathrm{~nm}$ ) and Near InfraRed (NIR, 767-832 nm) wavelengths, and a Flir SC500/A40M thermal camera $(7.5-13 \mu \mathrm{m})$ for radiometric temperature estimation. The nominal pixel resolution was approximately $0.6 \mathrm{~m}$ for VIS/NIR acquisitions, and $1.7 \mathrm{~m}$ for the thermal-IR data.

Figure 3 shows the scheduling of the acquisitions (vertical black lines), along with the temporal trend of daily reference evapotranspiration ( $\mathrm{ET}_{0}$, green dotted line) computed by means of the FAO-56 proposed formulation (Allen et al., $1998)$ and total daily rainfall ( $P$, blue line) as was measured by the SIAS weather station. The $\mathrm{ET}_{0}$ analysis shows that the maximum atmospheric demands were almost constant at about $6 \mathrm{~mm} \mathrm{~d}^{-1}$ in June-July, and decreased linearly from the middle of August to a value of about $3 \mathrm{~mm} \mathrm{~d}^{-1}$ in October. This range of variability corresponds to potentially high vegetation stress conditions in the first period (characterized by absence of precipitation), followed by reduced atmosphere demand and moderate episodic rainfall in the second period (from the end of September to October). Of particular interest are the two moderate rainfall events (of about 10 and $25 \mathrm{~mm}$ ) that occur between the 5th (DOY 247) and the 6th (DOY 284) remote sensing acquisitions on DOY 258 and 267. These events made the last two acquisitions different from the previous overpasses in terms of water availability and consequently potential water stress conditions.

The application of the TSEB model requires a set of spatially distributed remotely sensed inputs that were derived from the airborne imagery. For this purpose the G, R and NIR bands of the 7 acquired images were radiometrically calibrated, and atmospheric influence removed by means of the empirical line method (Slater et al., 1996) using the spectroradiometric information collected by in-situ measurements. The multispectral images were used to derive the Normalized Difference Vegetation Index, NDVI (Rouse et al., 1973), and 


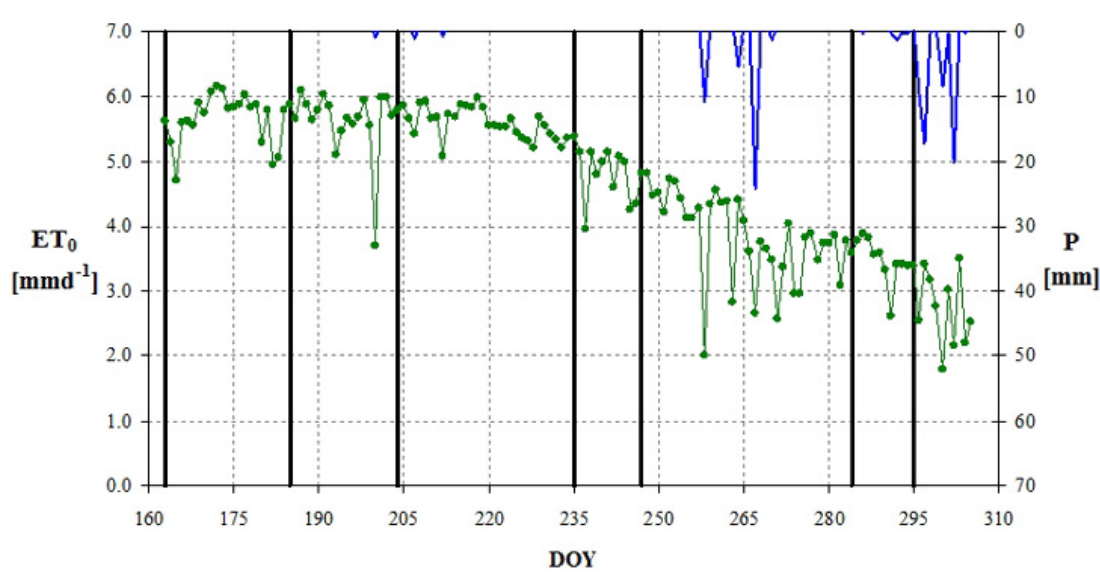

\begin{tabular}{ccc}
\hline $\begin{array}{c}\text { Date } \\
{[\mathrm{dd} / \mathrm{mm} / \mathrm{yyyy}]}\end{array}$ & DOY & $\begin{array}{c}\text { Time } \\
{\left[\text { local }^{*}\right]}\end{array}$ \\
\hline $11 / 06 / 2008$ & 163 & $13: 30$ \\
$03 / 07 / 2008$ & 185 & $11: 00$ \\
$22 / 07 / 2008$ & 204 & $11: 30$ \\
$22 / 08 / 2008$ & 235 & $12: 00$ \\
$03 / 09 / 2008$ & 247 & $11: 30$ \\
$10 / 10 / 2008$ & 284 & $11: 00$ \\
$21 / 10 / 2008$ & 295 & $11: 30$ \\
\hline *local time = UTC+2 & & \\
\hline
\end{tabular}

Fig. 3. Daily reference evapotranspiration (left panel, green line on the primary axis) and total rainfall (left panel, blue line on the secondary axis) for the study period derived from SIAS weather station measurements. Black vertical thick lines (left panel) highlight the airborne overpasses. Right panel table shows DOY of remote sensing data acquisitions and the mean time of airborne overpass.

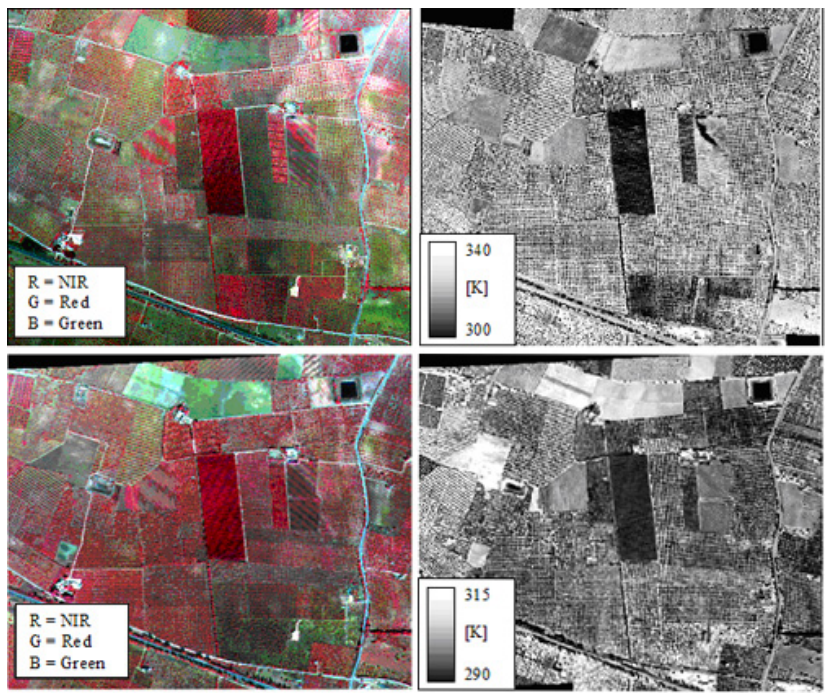

Fig. 4. Remote sensing images acquired during the first (DOY 163, upper line) and last (DOY 295, lower line) overpass. Left panels show false-colour composition of $\mathrm{R}=\mathrm{NIR}, \mathrm{G}=\mathrm{Red}, \mathrm{B}=$ Green reflectance bands at a spatial resolution of about $0.6 \mathrm{~m}$. Right panels show surface radiometric temperature maps at a spatial resolution of $1.7 \mathrm{~m}$.

the surface albedo by means of a weighted linear combination of the observed reflectances (Price, 1990). The approach proposed by Clevers (1989) was locally calibrated using the in-situ measurements in order to assess the LAI maps. Finally, the canopy heights have been retrieved by means of local calibrated LAI-based polynomial empirical relationship, as suggested by Anderson et al. (2004). Radiometric surface temperature $\left(T_{\mathrm{RAD}}\right)$ maps, primary input to the TSEB model, have been retrieved from the Flir instrument thermal band images using a linear regression between the acquired temperature and the in-situ measurements, adopting emissivity maps derived from NDVI on the basis of the approach proposed by Sobrino et al. (2007). Due to the fact that the adopted calibration procedures are widely used and validated, all the measurements were used to obtain the best calibration of the empirical relationships. In Table 2 are reported the coefficients of determination $\left(R^{2}\right)$ relative to the calibration procedures, highlighting the good performance obtained with the in-situ local calibration approaches.

Figure 4 shows false-colour composites of the three reflectance bands and the radiometric surface temperature maps for the 11 June 2008 (DOY 163) and 21 October 2008 (DOY 295) acquisitions. The comparison of the two falsecolour composition images highlights the increase of vegetation cover (red areas) due to weeds growing beneath the crop trees following the rainfall events on DOY 258 and 267. Rainfall effects are also reflected in the radiometric temperature maps, which show a general decrease in surface temperature in most areas due to increased vegetation cover and wetter soil conditions.

For use in the TSEB model, the temperature and biophysical parameters maps were aggregated and co-registered to a common resolution of $12 \mathrm{~m}$ to avoid spatial discrepancies between the multispectral and thermal datasets, following the suggestion of Anderson et al. (2004). Aggregated temperatures were retrieved averaging the surface radiance values, while other maps were aggregated through linear averaging. The resolution of $12 \mathrm{~m}$ was also selected in order to obtain a pixel dimension just greater than the average rows space, minimizing the presence of bare soil (or full covered) pixels inside sparse vegetation fields. In fact, at higher resolutions (on the order of $10^{0} \mathrm{~m}$ ), these areas are constituted by alternating fully vegetated and bare soil pixels, is not theoretically suitable for application of land surface formulations such as the TSEB, which were developed to be applied at 


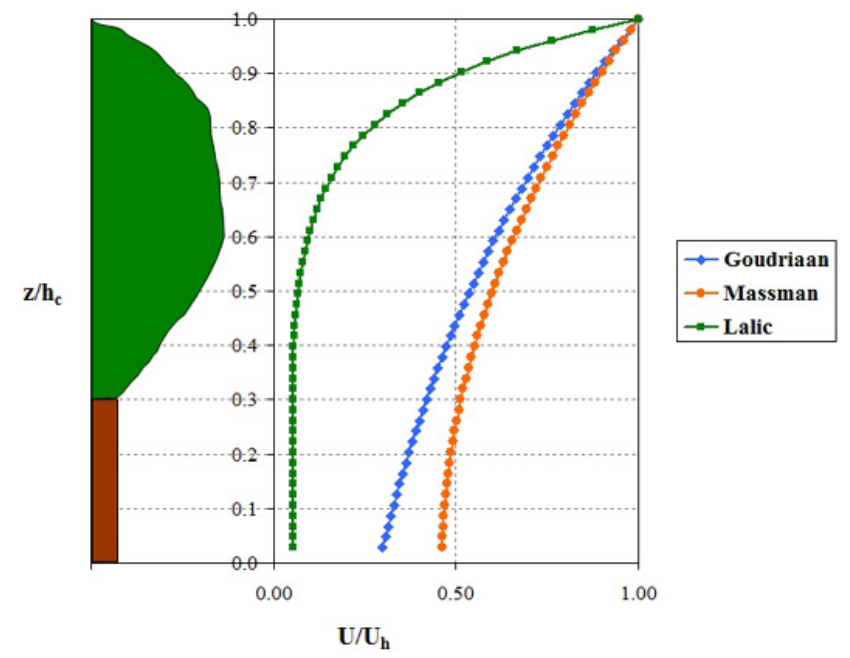

Fig. 5. Normalized in-canopy wind profiles retrieved using Goudriaan (blue), Massman (orange) and Lalic (green) schemes.

spatial scales $\left(\sim 10^{1}-10^{2} \mathrm{~m}\right)$ where there is radiation and turbulent exchange between soil and canopy components and surface-layer similarity defining the resistance formulations (e.g., Eq. 15) are applicable.

\section{Results and discussion}

In order to evaluate the effect of the estimated wind speed above the soil surface on the energy budget partitioning, the TSEB model was run for all the 7 dates using the three in-canopy wind profile formulations described in Sect. 2.2. Flux outputs from the TSEB using these three formulations were evaluated in comparison with measurements from the olive orchard, then differences in model output over the entire study areas were assessed for all the acquisition dates. Additionally, a preliminary sensitivity analysis of the three wind profile formulations has been performed.

\subsection{Analysis of wind extinction models}

Figure 5 compares in-canopy wind profiles obtained using the Goudriaan, Eq. (17), Massman, (Eq. 19 and Lalic, Eq. 21), models, generated using mean field properties retrieved for olive trees in the study site. For comparison purposes, elevation (agl) is normalized by canopy height, while wind speed is normalized with respect to the speed just above the canopy. In this way, both variables range between 0 and 1 .

These comparisons show that the Goudriaan and Massman approaches return very similar values in the upper canopy layer, with divergent results in the lower profiles characterized by higher wind speeds from the Massman relationship. The Lalic model exhibits a larger extinction in the upper layer
Table 4. NDVI mean and standard deviation (in brackets) for the Olive sub-fields and whole field ("All”), computed for the 7 airborne acquisition dates.

\begin{tabular}{ccccccc}
\hline DOY & O1 & O2 & O3 & O4 & O5 & All \\
\hline \multirow{2}{*}{163} & 0.43 & 0.41 & 0.43 & 0.41 & 0.38 & 0.41 \\
& $(0.06)$ & $(0.05)$ & $(0.05)$ & $(0.05)$ & $(0.06)$ & $(0.05)$ \\
185 & 0.40 & 0.39 & 0.40 & 0.41 & 0.37 & 0.39 \\
& $(0.05)$ & $(0.05)$ & $(0.05)$ & $(0.05)$ & $(0.05)$ & $(0.05)$ \\
204 & 0.39 & 0.39 & 0.40 & 0.40 & 0.36 & 0.39 \\
& $(0.05)$ & $(0.05)$ & $(0.05)$ & $(0.05)$ & $(0.05)$ & $(0.05)$ \\
235 & 0.41 & 0.39 & 0.41 & 0.40 & 0.37 & 0.40 \\
& $(0.05)$ & $(0.04)$ & $(0.05)$ & $(0.04)$ & $(0.05)$ & $(0.04)$ \\
247 & 0.46 & 0.41 & 0.45 & 0.43 & 0.38 & 0.43 \\
& $(0.06)$ & $(0.05)$ & $(0.05)$ & $(0.05)$ & $(0.05)$ & $(0.05)$ \\
284 & 0.50 & 0.46 & 0.53 & 0.51 & 0.48 & 0.50 \\
& $(0.04)$ & $(0.05)$ & $(0.05)$ & $(0.04)$ & $(0.05)$ & $(0.04)$ \\
295 & 0.51 & 0.47 & 0.54 & 0.54 & 0.51 & 0.51 \\
& $(0.04)$ & $(0.05)$ & $(0.04)$ & $(0.04)$ & $(0.05)$ & $(0.04)$ \\
\hline
\end{tabular}

and very low wind speeds in the lower portion of in-canopy airspace.

It should be stressed, however, that these comparisons are strongly influenced by the assumed canopy structure variables, especially LAI and canopy height. To better understand this dependence, model sensitivity to primary biophysical variables was evaluated. In particular we focus attention on the effect on above-soil speed $\left(U_{\mathrm{s}}\right)$, representing the variables of interest for TSEB model application.

Figure 6 shows variability in $U_{\mathrm{s}} / U_{\mathrm{c}}$ with changing values of LAI and $h_{\mathrm{c}}$, fixed inside the typical range of variability for Mediterranean agricultural crops. Looking at Fig. 6 we see that the Massman (middle panel) and Lalic (lower panel) models show low sensitivity to the assumed canopy height $\left(h_{\mathrm{c}}\right)$, while the Goudriaan (top panel) model shows wind speed reduction increasing non-linearly with canopy height. Moreover, the Goudriaan approach shows an almost linear dependence on LAI over this range, while the Massman and Lalic formulations show saturation in the extinction effect for higher values of LAI.

At all values of LAI and $h_{\mathrm{c}}$, the Lalic model generates the lowest values of $U_{\mathrm{s}}$ (as seen in Fig. 5). In contrast, the Goudriaan approach returns low values of $U_{\mathrm{s}}$ only under conditions of high LAI and $h_{\mathrm{c}}$, while the Massman model requires only high LAI for significant wind speed reduction.

The net effect is that the Lalic model will typically produce higher values of soil resistance $\left(r_{\mathrm{s}}\right)$, tending to reduce the influence of soil fluxes on the in-canopy microclimate. This will have the effect of reducing sensible heat flux estimates from the TSEB model under sparse canopy conditions where $R_{\mathrm{n}, \mathrm{s}}$ is relatively large. 


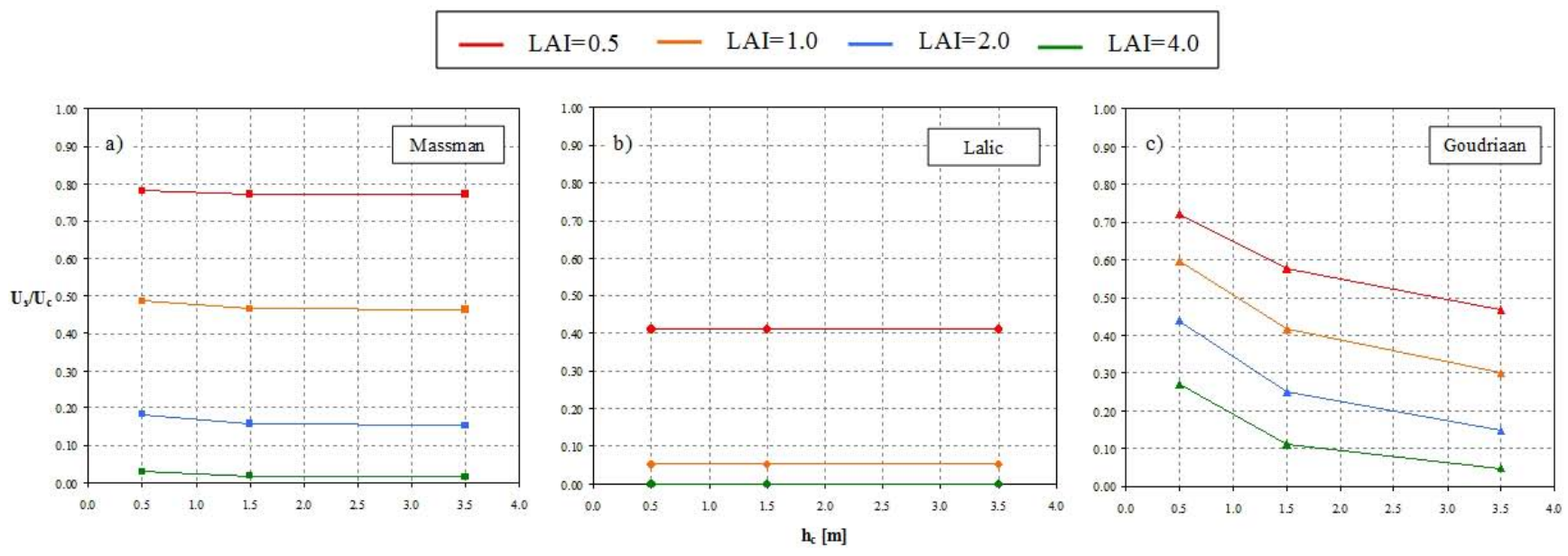

Fig. 6. Sensitivity of $U_{\mathrm{s}} / U_{\mathrm{c}}$ from the three selected in-canopy wind profile models to variations in LAI and $h_{\mathrm{c}}$. Panel (a) shows the results for Massman model (square dotted lines); panel (b) shows the results for Lalic model (circle dotted lines); panel (c) shows the results for Goudriaan model (triangle dotted lines).

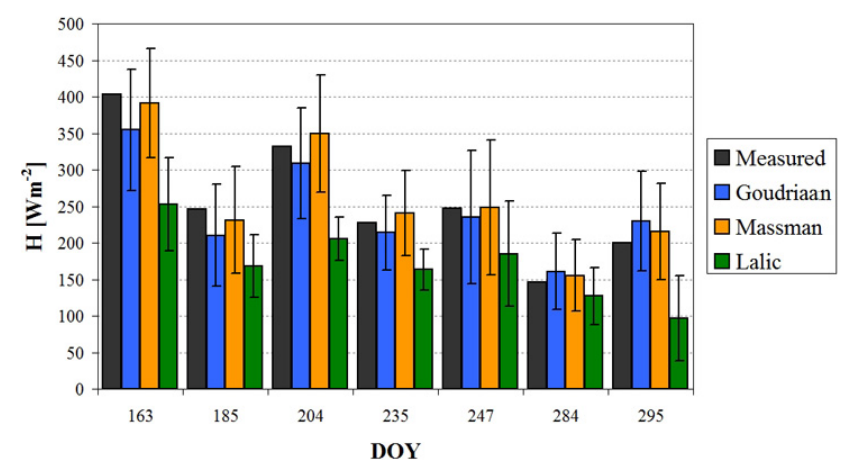

Fig. 7. Bar plot comparing measured and modelled sensible heat fluxes for the 7 acquisition dates. The modelled values correspond to the mean olive field values, while the error bars represent the standard deviation in modelled $H$ computed over the field polygon.

\subsection{Olive field validation}

As reported in Sect. 3.2.2, fluxes from the SAS and EC systems were averaged and are taken as reference values characterizing the entire olive orchard. To support the hypothesis of uniformity in this field, spatial variability in NDVI and $T_{\mathrm{RAD}}$ was assessed for each of the 5 sub-plots, O1 to O5, on all 7 acquisition dates.

The results of this analysis, reported in Tables 4 and 5, demonstrate that the deviation of single sub-plot mean values from the global mean is always lower than the standard deviation for both NDVI and $T_{\mathrm{RAD}}$. The only exception is for radiometric temperature in sub-plot $\mathrm{O} 4$ for the 3 rd acquisition (DOY 204). This behaviour can be explained by a break in the irrigation system a few days before the airborne overpass, which caused a localized reduction of soil surface temperature. Fortunately, the mean wind direction during the DOY
Table 5. $T_{\mathrm{RAD}}$ mean and standard deviation (in brackets) for the Olive sub-fields and whole field ("All") $\left[{ }^{\circ} \mathrm{C}\right]$, computed for the 7 airborne acquisition dates.

\begin{tabular}{ccccccc}
\hline DOY & O1 & O2 & O3 & O4 & O5 & All \\
\hline \multirow{2}{*}{163} & 46.78 & 44.52 & 45.78 & 44.74 & 46.27 & 45.62 \\
& $(2.71)$ & $(2.02)$ & $(3.00)$ & $(1.99)$ & $(2.02)$ & $(2.35)$ \\
185 & 44.53 & 43.40 & 42.41 & 42.55 & 44.39 & 43.46 \\
& $(2.73)$ & $(2.11)$ & $(2.58)$ & $(2.00)$ & $(2.10)$ & $(2.30)$ \\
204 & 43.23 & 42.27 & 42.19 & 38.90 & 43.52 & 42.02 \\
& $(2.03)$ & $(2.18)$ & $(2.24)$ & $(3.67)$ & $(1.84)$ & $(2.39)$ \\
235 & 41.41 & 44.24 & 43.51 & 44.90 & 45.00 & 43.81 \\
& $(2.87)$ & $(1.67)$ & $(1.91)$ & $(1.75)$ & $(1.73)$ & $(1.99)$ \\
247 & 40.92 & 42.10 & 40.10 & 42.36 & 41.39 & 41.37 \\
& $(2.34)$ & $(2.00)$ & $(2.68)$ & $(2.30)$ & $(1.92)$ & $(2.25)$ \\
284 & 27.79 & 28.30 & 27.82 & 29.39 & 29.18 & 28.50 \\
& $(0.97)$ & $(0.96)$ & $(1.15)$ & $(1.25)$ & $(1.27)$ & $(1.12)$ \\
295 & 28.79 & 29.41 & 27.59 & 29.02 & 28.24 & 28.61 \\
& $(1.93)$ & $(1.43)$ & $(1.83)$ & $(2.07)$ & $(1.78)$ & $(1.81)$ \\
\hline
\end{tabular}

204 precludes the possibility that the instrument source areas include this sub-plot. For this acquisition, TSEB results from sub-plot $\mathrm{O} 4$ have been removed from spatial averages.

On the basis of this analysis of spatial variability, the flux maps retrieved by the TSEB model using the three incanopy wind profile models were spatially averaged over the whole field (with the mentioned exception), and mean values were compared with the average EC-SAS measurements computed over a $2 \mathrm{~h}$ window centered at the time of the overpasses.

Figure 7 shows a histogram of the mean observed sensible heat flux for each remote sensing acquisition date, along with modelled values obtained using the 3 wind profile 

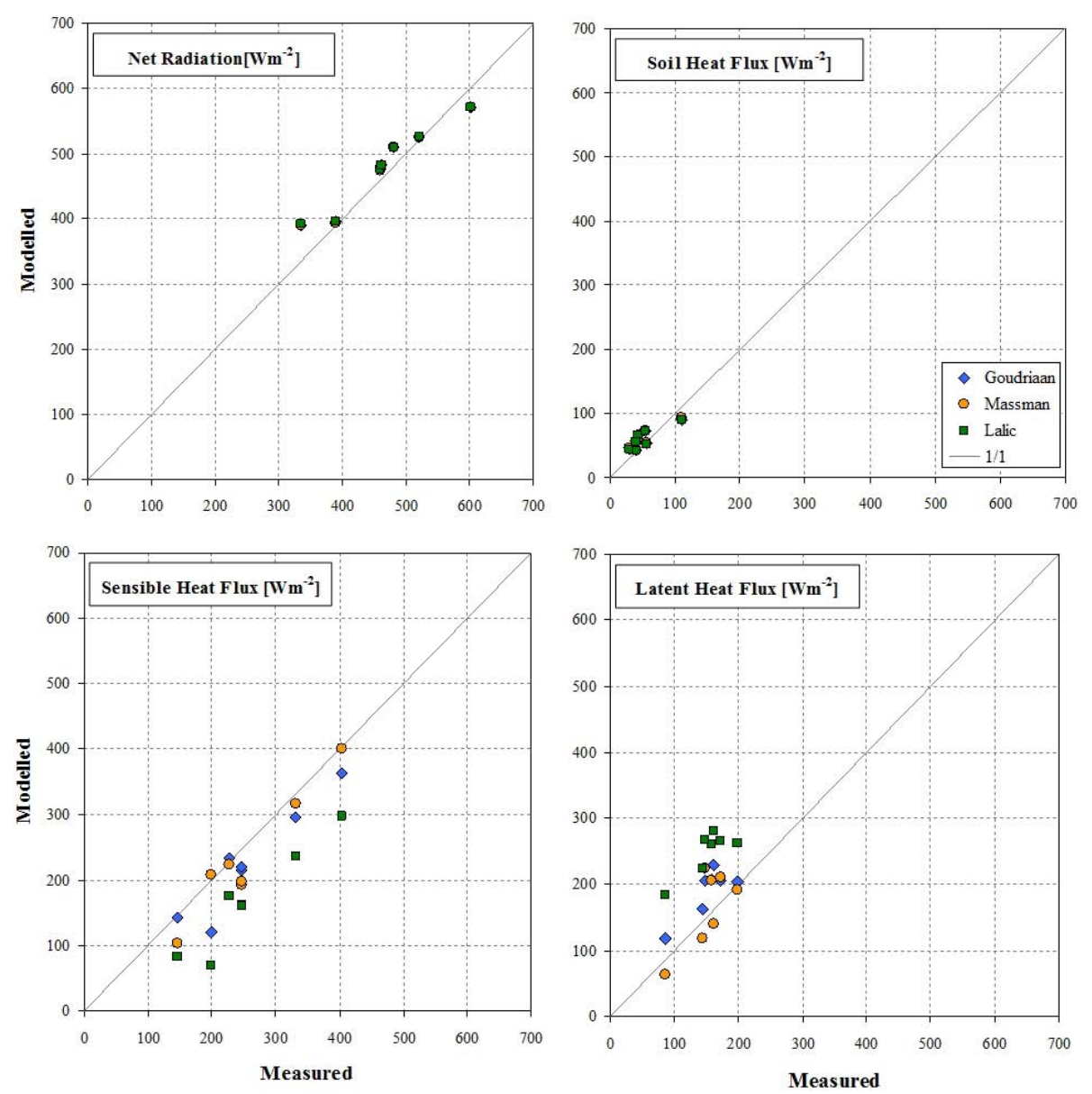

Fig. 8. Scatterplots of measured vs. modelled net radiation (upper left panel), soil heat flux (upper right panel), sensible heat flux (lower left panel) and latent heat flux (lower right panel) using the three different in-canopy wind profile models.

formulations. This plot shows that in these cases the Massman and Goudriaan approaches yield values very close to the measurements. In contrast, the Lalic approach yields relatively poor flux estimates.

Statistical comparisons between modelled and measured fluxes are shown in Table 6. In terms of both RMSD and MAD, the Massman approach yields the lowest errors in sensible and latent heat flux. The Goudriaan approach, used in the standard implementation of the TSEB, also returns reasonable estimates in $H$ and $\lambda E$, comparable with the measurement uncertainties (see Table 3). In contrast, the Lalic incanopy wind profile model yields unacceptably high errors with respect to measured fluxes.

The statistics in Table 6 also suggest that the TSEB yields reasonable estimates of net radiation and soil heat flux, and that model-measurement agreement for flux components is not very sensitive to the choice of in-canopy wind profile law in this case.

Figure 8 compares measured vs. modelled fluxes via scatterplots. Both modelled net radiation and soil heat flux show good agreement with measured fluxes. For sensible heat, both the Goudriaan and Massman models provide reasonable estimates while the Lalic model underestimates $H$ by $90 \mathrm{~W} \mathrm{~m}^{-2}$ on average. This results in an overestimation of latent heating by the Lalic model, whereas the Massman and Goudriaan approaches both return reliable results for $\lambda E$.

It should be noted that results from the Massman model are related to the choice of the $\alpha_{*}$ parameters in Eq. (20), which can change considerably for different land uses. This will contribute additional complexity in spatially distributed applications of TSEB, because of the introduction of an additional parameter that is not easily retrievable from remote sensing data.

\subsection{Study area model comparisons}

As highlighted in Sect. 4.1, differences between the three incanopy wind profile laws can depend strongly on values assumed for LAI and $h_{\mathrm{c}}$ for the analyzed crop. This is further demonstrated in the pixel-by-pixel scatterplots shown in Fig. 9, representing an analysis of model results over the entire study area. Figure 9 shows comparisons of $H$ 
Table 6. RMSD and MAD statistics $\left[\mathrm{W} \mathrm{m}^{-2}\right.$ ] computed using TSEB modelled and EC-SAS measured values collected during the 7 acquisition dates over the olive field.

\begin{tabular}{lcc|cc|cc|cc}
\hline \multirow{2}{*}{ Model } & \multicolumn{2}{c|}{$R_{n}$} & \multicolumn{2}{c|}{$G_{0}$} & \multicolumn{2}{c|}{$H$} & \multicolumn{2}{c}{$\lambda E$} \\
\cline { 2 - 9 } & RMSD & MAD & RMSD & MAD & RMSD & MAD & RMSD & MAD \\
\hline Goudriaan & 28 & 23 & 17 & 15 & 40 & 32 & 43 & 37 \\
Massman & 28 & 23 & 16 & 14 & 32 & 25 & 40 & 34 \\
Lalic & 29 & 23 & 17 & 15 & 92 & 89 & 98 & 96 \\
\hline
\end{tabular}
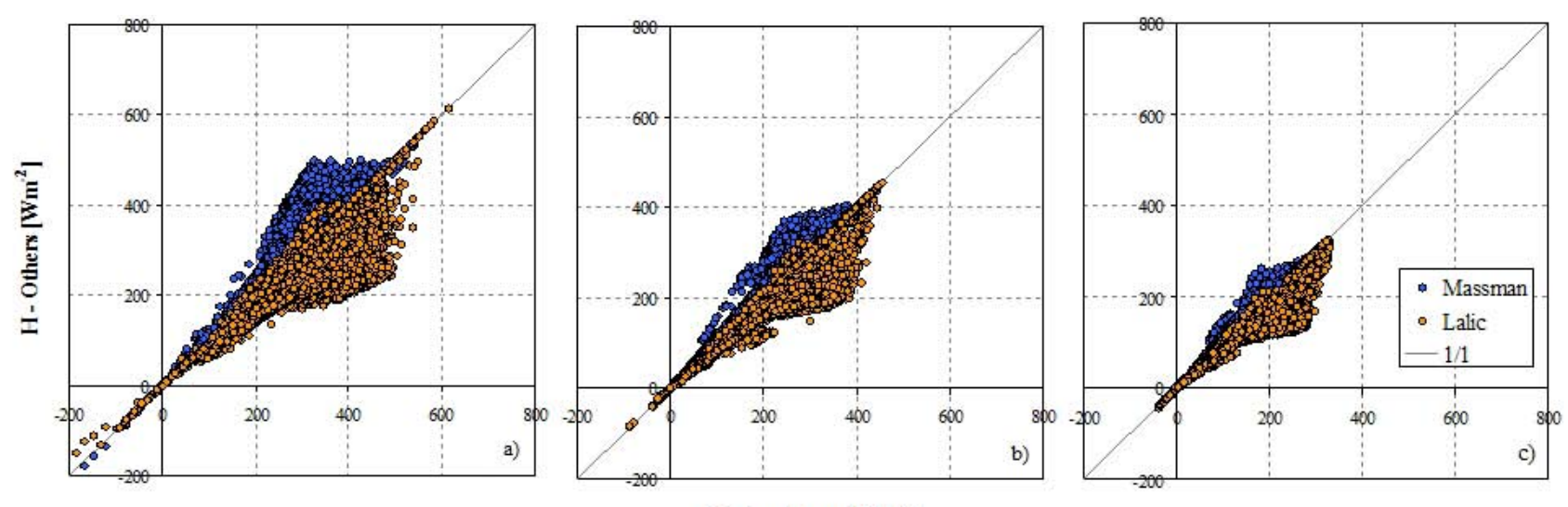

H-Goudriaan $\left[\mathrm{Wm}^{-2}\right]$

Fig. 9. Scatterplots of sensible heat fluxes from Goudriaan models vs. Massman and Lalic models, for the 3rd acquisition (panel a, higher wind speed), 2nd acquisition (panel $\mathbf{b}$, middle-range wind speed) and 7th acquisition (panel $\mathbf{c}$, lower wind speed).

fluxes estimated for the airborne acquisition under higher wind speed conditions (3rd acquisition, DOY 204), moderated wind (2nd acquisition, DOY 185) and lower wind speed (7th acquisition, DOY 295).

The plots of Fig. 9 show that the Massman model generally returns the highest values of sensible heat, whereas the Lalic model yields the lowest $H$. Moreover, the differences between the three models are largest for mid-range $H$ values, generally associated with areas of moderate vegetation cover (approximately in the range 0.15-0.50). Additionally model discrepancies are largest under the highest wind speed conditions.

Finally, illustrated in Fig. 10 are differences between crop types in how choice of in-canopy wind profile model impacts modelled $H$, showing mean sensible heat flux estimated by each model for citrus fields $\mathrm{C} 1$ and $\mathrm{C} 2$ and vineyards $\mathrm{V} 1$ and V2 demarcated in Fig. 2. Obviously the absence of flux measurements in citrus and vineyards fields allows only a comparative model vs. model examination on these fields. Differences are relatively small for field $\mathrm{C} 1$, characterized by high LAI, probably due to the fact that soil sensible heat fluxes contributions are negligible for this canopy coverage condition. Field $\mathrm{C} 2$ also had high LAI, but lower than field $\mathrm{C} 1$; in this case, differences in $H$ estimated using the Lalic model are more significant.
On most days, the three in-canopy wind profile models yield similar estimates of $H$ for vineyard field V1. This field has very low canopy coverage, with only moderate extinction in the foliage air-space. In contrast, the vineyard in field V2 had moderate canopy coverage, more comparable to the olive groves examined in earlier sections. In this case, the Lalic model predicts the largest extinction effects and therefore the lowest estimates of sensible heat flux, similar to the olive cases.

In summary, significant differences in system sensible heat estimated using the three wind profile models are found only for canopies characterized by moderate vegetation coverage. For higher cover fields, the soil sensible heat flux contributions become negligible, whereas for low vegetation cover fraction, the canopy extinction effects on near-surface wind speed are minor.

\section{Conclusions}

A set of 7 high resolution multispectral airborne remote sensing images and associated in-situ measurements have been collected over an agricultural area in the southern part of Sicily, characterized by a typical Mediterranean climate. This dataset has been used to evaluate the behaviour of the TSEB model over fields with sparse, tall vegetation, such as 
$\square$ Goudriaan $\square$ Massman $\square$ Lalic
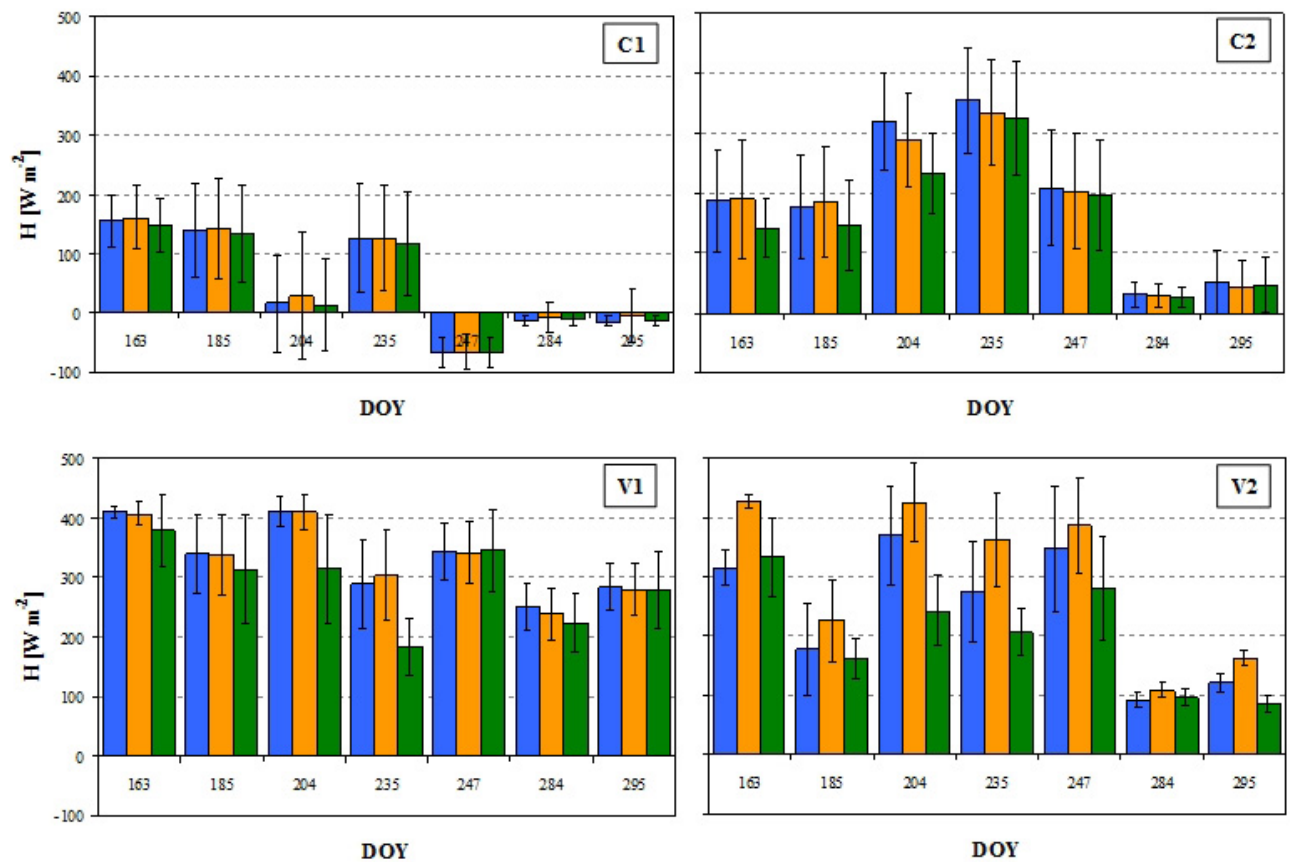

Fig. 10. Bar plot comparing modelled sensible heat flux for the 7 acquisition dates for the fields: C1 (upper-left panel) C2 (upper-right panel), V1 (lower-left panel) and V2 (lower-right panel). See Fig. 2 for the field locations. Error bars represent the standard deviation in modelled $H$, computed over the field polygon.

orchards and vineyards. For such canopy architectures, a detailed analysis of flux exchanges in the air space between canopy crown and soil surface can provide valuable insight into the surface energy budget partitioning.

The goal of this work was to assess sensitivity of TSEB flux estimates to the modelling of the wind speed just above the soil using three different approaches: the Goudriaan in-canopy wind profile model (1977) used in the original TSEB formulation, the Massman (1987) model, and the Lalic et al. (2003) formulation. Evaluation of the three models was performed over an olive field where micrometeorological measurements were collected throughout the growing season using a small aperture scintillometer and an eddy covariance installation.

Analysis of the results indicates the best agreement with measured sensible heat flux was obtained using the approach proposed by Massman, with errors, quantified by means of RMSD and MAD indices, on the order of $20 \mathrm{~W} \mathrm{~m}^{-2}$ for all energy flux components, comparable with uncertainties expected in the measurements themselves. However, the simpler Goudriaan model also yielded reasonable estimates of the sensible and latent heat fluxes, with somewhat larger errors than the Massman approach but still comparable with the measurements uncertainties. In contrast, results from the TSEB model using the Lalic formulation were poor, especially for high values of sensible heat fluxes values associated with day characterized by high wind speed conditions.
The Lalic model predicts strong extinction of winds through the canopy, and therefore low wind speed at the soil surface and therefore low soil sensible heat flux contributions. The Massman and Goudriaan models predict similar wind speed profiles, with the Massman model generally returning lower extinction and higher sensible heat flux values that were in better agreement with measured fluxes. Differences in flux estimates using the three models were largest for high wind speeds and mid-range flux conditions.

To better understand the correlation between canopy parameters and model differences, model flux estimates were compared over 4 additional fields where no fluxes measurements were available, characterized by different vegetation coverage and crop type, including citrus groves and vineyards. This analysis suggests that in-canopy wind profile model discrepancies become relevant, in terms of impact on modelled sensible heat flux, only for sparse canopies with moderate vegetation coverage. This finding can be explained by the negligible contribution of soil sensible heat flux in the case of high coverage, and by the minimal wind extinction effect in the case of very sparse vegetation.

While the Massman model yielded better agreement with observed fluxes in this study, the simpler Goudriaan approach provided comparable results using fewer parameters. The Massman model requires a parameter accounting for roughness sub-layer of the underlying vegetative surface, the value of which will be difficult to specify accurately 
in spatially distributed applications of the TSEB. For localscale applications, the Massman model may provide better results.

Further tests of in-canopy wind profile parameterization within the TSEB model will incorporate forested land cover classes and a range of surface moisture conditions to better understand sensitivity to canopy architecture and soil surface conditions. In the near future, the study will be extended in detail for crops characterized by a strong row structure, such as vineyards, to assess the role of wind direction in flux exchanges. In order to more rigorously evaluate these wind extinction models under a range of canopy conditions, a series of wind profile measurements will be collected under different cropping systems. Such measurements will improve our understanding of these exchange processes under clumped vegetation conditions.

Acknowledgements. The authors thank the ENEA (Ente per le Nuove Tecnologie, l'Energia e l'Ambiente) for the helpful collaboration in the scintillometer installation management, the IBIMET (Istituto di Biometeorologia) of CNR-Bologna and the DCA (Dipartimento di Colture Arboree) of the Università degli Studi di Palermo for the eddy covariance installation management, and the farm "Rocchetta di Angelo Consiglio" for kindly hosting the experiment. This work was partially funded by the DIFA projects of the Sicilian Regional Government within the Accordo di Programma Quadro "Società dell'Informazione".

Edited by: D. F. Prieto

\section{References}

Abramowitz, M. and Stegun, I. A.: Handbook of Mathematical Functions, National Bureau of Standards Applied Math. Ser., n. 55, Washington, DC, 1046 pp., 1964.

Allen, R. G., Pereira, L. S., Raes, D., and Smith, M.: Crop evapotranspiration, Guideline for computing crop water requirements, FAO irrigation and drainage paper n. 56, Rome, Italy, 326 pp., 1998.

Allen, R. G., Tasumi, M., and Trezza, R.: Satellite-based Energy balance for Mapping Evapotranspiration with Internalized Calibration (METRIC)-model, J. Irrigation Drain. Eng., 133(4), 380394, 2007.

Anderson, M. C., Neale, C. M. U., Li, F., Norman, J. M., Kustas,W. P., Jayanthi, H., and Chavez, J.: Upscaling ground observations of vegetation water content, canopy height, and leaf area index during SMEX02 using aircraft and Landsat imagery, Rem. Sens. Environ., 92, 447-464, 2004.

Bastiaanssen, W. G. M., Menenti, M., Feddes, R. A., and Holtslag, A. A. M.: The Surface Energy Balance Algorithm for Land (SEBAL): Part 1 formulation, J. Hydrol., 212, 198-212, 1998.

Bastiaanssen, W. G. M. and Bos, M. G.: Irrigation performance indicators based on remotely sensed data: a review of literature, Irrigation and drainage systems, 13, 291-311, 1999.

Brutsaert, W.: Evaporation into the atmosphere: Theory, history and applications, D. Reidel Publ. Co., Dordrecht, 308 pp., 1982.

Campbell, G. S. and Norman J. M.: An introduction to environmental biophysics, Springer-Verlag, 286 pp., 1998.
Cellier, P., Richard, G., and Robin, P.: Partition of sensible heat fluxes into bare soil and the atmosphere, Agric. For. Meteorol., 82, 245-265, 1996.

Chehbouni, A., Nouvellon, Y., Lhomme, J. -P., Watts, C., Boulet, G., Kerr, Y. H., Moran, M. S., and Goodrich, D. C.: Estimation of surface sensible heat flux using dual angle observations of radiative surface temperature, Agric. For. Meteorol., 108, 55-65, 2001.

Choi, M., Kustas, W. P., Anderson, M. C., Allen, R. G., Li, F., and Kjaersgaard, J. H.: An intercomparison of three remote sensingbased surface energy balance algorithms over a corn and soybean production region (Iowa, US) during SMACEX, Agric. For. Meteorol., 149(12), 2082-2097, 2009.

Choudhury, B. J.: Relationships between vegetation indices, radiation absorption, and net photosynthesis evaluated by a sensitivity analysis, Rem. Sens. Environ., 22, 209-233, 1987.

Choudhury, B. J., Idso, S. B., and Reginato, R. J.: Analysis of an empirical model for soil heat flux under a growing wheat crop for estimating evaporation by an infrared-temperature based energy balance equation, Agric. For. Meteorol., 39, 283-297, 1987.

Clevers, J. G. P. W.: The application of a weighted infrared-red vegetation index for estimating leaf area index by correcting for soil moisture, Rem. Sens. Environ., 29, 25-37, 1989.

Cowan, I. R.: Mass, heat and momentum exchange between stands of plants and their atmospheric environment, Quart. J. Roy. Meteorol. Soc., 94, 523-544, 1968.

de Bruin, H. A. R. and Moore, C. J.: Zero-plane displacement and roughness length for tall vegetation, derived from a simple mass conservation hypothesis, Boundary-Layer Meteorol., 42, 53-62, 1985.

Foken, T., Wimmer, F., Mauder, M., Thomas, C., and Liebethal, C.: Some aspects of the energy balance closure problem, Atmos. Chem. Phys., 6, 4395-4402, doi:10.5194/acp-6-4395-2006, 2006.

Fons, W. L.: Influence of forest cover on wind velocity, J. Forestry, 38, 481-487, 1940.

Friedl, M. A.: Relationships among remotely sensed data, surface energy balance, and area-averaged fluxes over partially vegetated land surfaces, J. Appl. Meteorol., 35, 2091-2103, 1996.

Fritschen, L. J.: Characterization of boundary conditions affecting forest environmental phenomena, in: the forest-atmosphere interaction, edited by: Hutchinson, B. A. and Hicks, B. B., D. Reidel Publishing Company, Holland, 3-23, 1985.

Goudriaan, J.: Crop micrometeorology: a simulation study, Center Agricoltural Publications and Documentation, Wageningen Universitait, 1977.

Hartogensis, O.: Exploring scintillometry in the stable atmospheric surface layer, PhD thesis, Wageningen Universitait, 240 pp., 2006.

Kalma, J. D., McVicar, T. R., and Mccabe, M. F.: Estimating land surface evaporation: a review of methods using remotely sensed surface temperature data, Surv. Geophys., 29(4-5), 421-469, 2008.

Kondo, J. and Ishida, S.: Sensible heat flux from the earth's surface under natural convective conditions, J. Atmos. Sci., 54, 498-509, 1997.

Kustas, W. P. and Daughtry, C. S. T.: Estimation of the soil heat flux/net radiation ratio from spectral data, Agric. For. Meteorol., 49, 205-223, 1990. 
Kustas, W. P. and Norman, J. M.: Use of remote sensing for evapotranspiration monitoring over land surface, Hydrolog. Sci. J., 41, 495-516, 1996.

Kustas, W. P. and Norman, J. M.: Evaluation of soil and vegetation heat flux predictions using a simple two-source model with radiometric temperatures for partial canopy cover, Agr. For. Meteorol., 99, 13-29, 1999.

Kustas, W. P. and Norman, J. M.: A two-source energy balance approach using directional radiometric temperature observations for sparse canopy covered surface. Agron. J., 92, 847-854, 2000.

Kustas, W. P., Norman, J. M., Shmugge, T. J., and Anderson, M. C.: Mapping surface energy fluxes with radiometric temperature, (Chapter 7), in: Thermal remote sensing in land surface processes, edited by: Quattrocchi, D. A. and Luvall, J. C., 205253, Boca Raton, Florida: CRC Press, 2004.

Lalic, B., Mihailovic, D. T., Rajkovic, B., Arsenic, I. D., and Radlovic, D.: Wind profile within the forest canopy and in the transition layer above it, Environ. Modelling and Software, 18, 943-950, 2003.

Li-cor Inc.: LAI-2000 plant canopy analyzer operating manual, Licor Inc., Lincoln, Nebraska, USA, 179 pp., 1992.

Massman, W.: A comparative study of some mathematical models of the mean wind structure and aerodynamic drag of plant canopies, Boundary-Layer Meteorol., 40, 179-197, 1987.

McNaughton, K. G. and van den Hurk, B. J. J. M.: A "Lagrangian" revision of the resistors in the two-layer model for calculating the energy budget of a plant canopy, Boundary-Layer Meteorol., 74, 262-288, 1995.

Minacapilli, M., Agnese, C., Blanda, F., Cammalleri, C., Ciraolo, G., DUrso, G., Iovino, M., Pumo, D., Provenzano, G., and Rallo, G.: Estimation of actual evapotranspiration of Mediterranean perennial crops by means of remote-sensing based surface energy balance models, Hydrol. Earth Syst. Sci., 13, 1061-1074, doi:10.5194/hess-13-1061-2009, 2009.

Mood, A., Graybill, F., and Boes, D.: Introduction to the Theory of Statistics (3rd Ed.), McGraw-Hill, 229 pp., 1974.

Norman, J. M. and Campbell, G. S.: Application of a plant environment model to problems in irrigation, in: Advances in Irrigation Academic Press, NY, edited by: Hillel, D. I., 155-188, 1983.

Norman, J. M., Kustas, W. P., and Humes K. S.: Source approach for estimating soil and vegetation energy fluxes in observations directional radiometric surface temperature, Agr. For. Meteorol., 77, 263-293, 1995.

Papale, D.: Il progetto CarboItaly: una rete nazionale per la misura di sink forestali e agricoli italiani e lo sviluppo di un sistema di previsione dell'assorbimento dei gas serra, Forest@, 3(2), 165167, 2006

Paulson, C. A.: The mathematical representation of wind speed and temperature profiles in the unstable atmospheric surface layer, Appl. Meteorol., 9, 857-861, 1970.

Pernice, F., Motisi, A., Rossi, F., Georgiadis, T., Nardino, M., Fontana, G., Dimino, G., and Drago, A.: Micrometeorological and sap flow measurement of water vapour exchanges in olive: scaling up from canopy to orchard, Acta Hort., 846, 159-166, 2009.

Petit, C., Trinite, M., and Valentin, P.: Study of turbulent diffusion above and within a forest-application in the case of $\mathrm{SO}_{2}$, Atmos. Environ., 10, 1057-1063, 1976.

Priestley, C. H. B. and Taylor, R. J.: On the assessment of surface heat flux and evaporation using large-scale parameters, Mon. Weather Rev., 100, 81-92, 1972.

Price, J. C.: Information content of soil spectra, Rem. Sens. Environ., 33, 113-121, 1990.

Prueger, J. H., Hatfield, J. L., Kustas, W. P., Hipps, L. E., MacPherson, J. I., and Parkin, T. B.: Tower and aircraft eddy covariance measurements of water vapour, energy and carbon dioxide fluxes during SMACEX, J. Hydrometeorol., 6, 954-960, 2005.

Raupach, M. R. and Thom, A. S.: Turbulence in and above plant canopies, Ann. Rev. Fluid Mech., 13, 97-129, 1981.

Richter, K. and Timmermans, W. J.: Physically based retrieval of crop characteristics for improved water use estimates, Hydrol. Earth Syst. Sci., 13, 663-674, doi:10.5194/hess-13-663-2009, 2009.

Roerink, G. J., Su, Z., and Menenti, M.: S-SEBI: a simple remote sensing algorithm to estimate the surface energy balance, Phys. Chem. Earth, 25(2), 147-157, 2000.

Ross, J.: Radiative transfer in plant communities, in: vegetation and atmosphere, edited by: Monteith, J. L., Academic press, London, 13-55, 1975.

Rouse, J. W., Haas, R. H., Schell, J. A., and Deering, D. W.: Monitoring vegetation systems in the Great Plains with ERTS, Third ERTS Symposium, NASA SP-351 I, 309-317, 1973.

Santanello, Jr., J. A. and Friedl, M. A.: Diurnal covariation in soil heat flux and net radiation, B. Am. Meteorol. Soc., 42, 851-862, 2003.

Sauer, T. J.: Sensible and latent heat exchange at the soil surface beneath a maize canopy, Ph.D. Thesis, University of Wisconsin, Madison, WI, 292 pp., 1993.

Sauer, T. J., Norman, J. M., Tanner, C. B., and Wilson, T. B.: Measurement of heat and vapour transfer at the soil surface beneath a maize canopy using source plates, Agric. For. Meteorol., 75, 161-189, 1995.

Schmugge, T. J., Kustas, W. P., Ritchie, J. C., Jackson, T. J., and Rango, A.: Remote sensing in hydrology, Adv. Water Resour., 25, 1367-1385, 2002.

Shaw, R. H.: Secondary Wind Speed Maxima Inside Plant Canopies, J. Appl. Meteorol., 16, 514-521, 1977.

Shuttleworth, W. J. and Wallace, J. S.: Evaporation from sparse crops - an energy combination theory, Quart. J. Roy. Meteorol. Soc., 111, 839-855, 1985.

Slater, P., Biggar, S., Thome, K., Gellman, D., and Spyak, P.: Vicarious radiometric calibrations of EOS sensors, J. Atmos. Ocean Tech., 13, 349-359, 1996.

Sobrino, J. A., Jiménez-Munõz, J. C., Sòria, G., Romaguera, M., Guanter, L., and Moreno, J.: Land surface emissivity retrieval from different VNIR and TIR sensors, IEEE T. Geosci. Remote, 46(2), 316-327, 2007.

Thiermann, V. and Grassl, H.: The measurement of turbulent surface-layer fluxes by use of bichromatic scintillation, Boundary-Layer Meteorol., 58, 367-389, 1992.

Timmermans, W. J., Kustas, W. P., Anderson, M. C., and French, A. N.: An intercomparison of the Surface Energy Balance Algorithm for Land (SEBAL) and the Two-Source Energy Balance (TSEB) modelling schemes, Rem. Sens. Environ., 108(4), 369384, 2007.

Twine, T. E., Kustas, W. P., Norman, J. M., Cook, D. R., Houser, P. R., Meyers, T. P., Prueger, J. H., Starks, P. J., and Wesely, M. L.: Correcting eddy covariance flux underestimates over a grassland, 
Agric. For. Meteorol., 103(3), 279-300, 2000.

Uchijima, Z. and Wright, J. L.: An experimental study of air flow in a corn plant-air layer, Bull. Natn. Inst. Agric. Sci., Tokio, Ser. A, 11, 19-66, 1964.
Webb, E. K.: Profile relationships: the log-linear range, and extension to strong stability, Q. J. Roy. Meteor. Soc., 96, 67-90, 1970. 